\title{
Impact of lightning surge on surge arrester placement in high voltage substation
}

\begin{abstract}
This study generalizes the modeling details to be used in modeling the high voltage substation and performing the analysis on the impact of lightning surge on surge arrester placement in high voltage substation using the PSCAD/EMTDC software. Modeling parameters and the substation layout design are based and adapted from $132 \mathrm{kV}$ substation in Johor Baharu, Malaysia, courtesy of the Tenaga Nasional Berhad (TNB). The model is based on single phase line model as it was suggested by the IEEE to be adequate to represent the substation in transient analysis simulation. The outcome of this paper would be the results of prediction of the breakdown current and effect of surge arrester placement in terms of voltage level measured at particular points in substation.
\end{abstract}

Keyword: Insulation coordination; Lightning; Surge arrester; PSCAD/EMTDC 